\title{
Factors Associated With Pesticide Safety Practices in Farmworkers
}

\author{
Larkin L. Strong, $\mathrm{PhD}, \mathrm{MPH}^{,}{ }^{1}$ Beti Thompson, $\mathrm{PhD}^{2,3}$ \\ Thomas D. Koepsell, MD, MPH, ${ }^{3,4}$ and Hendrika Meischke, $\mathrm{PhD}, \mathrm{MPH}^{2,3}$
}

Background Farmworkers and their families are exposed to pesticides through multiple pathways. Few studies have examined the frequency with which farmworkers engage in pesticide safety practices and the factors associated with their adoption.

Methods Using a large sample of farmworkers $(n=554)$, we evaluated relationships between pesticide safety behaviors and farmworkers' beliefs, training history, handling of pesticides at work, perceived occupational exposure, and employers' provision of personal protective equipment.

Results Performing behaviors at work was determined largely by whether personal protective equipment was provided. For home behaviors, female gender, living in a labor camp, being trained in the last 5 years, handling pesticides directly, and not perceiving organizational barriers to protecting oneself were associated with taking more precautions.

Conclusions These findings call for interventions that involve and engage multiple stakeholders to increase adoption of pesticide safety behaviors and reduce pesticide exposure in farmworkers. Am. J. Ind. Med. 51:69-81, 2008. ๑ 2007 Wiley-Liss, Inc.

KEY WORDS: farmworker; field worker; pesticide exposure; safety practices; takehome pathway

Work conducted while LL Strong was at the School of Public Health and Community Medicine, University of Washington, and the Fred Hutchinson Cancer Research Center. Abbreviations: WPS, Worker Protection Standard; PPE, personal protective equipment

${ }^{1}$ Department of Health Management and Policy, University of Michigan School of Public Health, Ann Arbor, Michigan

${ }^{2}$ Cancer Prevention Research Program, Fred Hutchinson Cancer Research Center, Seattle, Washington

${ }^{3}$ Department of Health Services, School of Public Health and Community Medicine, University of Washington, Seattle, Washington

${ }^{4}$ Department of Epidemiology, School of Public Health and Community Medicine, University of Washington, Seattle, Washington

Contract grant sponsor: US Environmental Protection Agency; Contract grant number: R826886; Contract grant sponsor: National Institutes of Environmental Health; Contract grant number: P01 ES09601; Contract grant sponsor: National Institute for Occupational Safety and Health; Contract grant number: T42 CCT010418.

${ }^{*}$ Correspondence to: Larkin L. Strong, School of Public Health, University of Michigan, 109 Observatory, SPH II, M3055, Ann Arbor, Ml 48109-2029. E-mail: LLstrong@umich.edu

Accepted 19 July 2007

DOI 10.1002/ajim.20519. Published online in Wiley InterScience

(www.interscience.wiley.com)

\section{INTRODUCTION}

Exposure to pesticides represents an important source of morbidity in farmworkers [Cordes and Foster, 1988; Moses, 1989; Mobed et al., 1992; Keifer et al., 2004]. Farmworkers may be occupationally exposed to pesticides through direct contact with chemicals, contact with pesticide residue on treated crops or equipment, drift, and entering treated fields before it is safe. Recently, studies have investigated pesticide exposure in family members of farmworkers, underscoring the health risks for this population. In addition to exposure pathways involving diet, residential pesticide use, and drift, family members may be exposed through a "take-home" pathway, in which occupational exposures are transported to the home by pesticide residue on farmworkers' clothing, boots, skin, and in their work vehicles [Simcox et al., 1995; Lu et al., 2000; Curl et al., 2002; Thompson et al., 2003]. Pesticide residue in the home, which is shielded from degradation by the sun and rain [Simcox et al., 1995], is of concern for all household members but particularly children 
because of their higher metabolic rate and distinct hand-tomouth behaviors [Eskenazi et al., 1999; Faustman et al., 2000].

Evidence for the take-home pathway is provided by studies investigating pesticide residue in home environments and pesticide metabolites in household members. Studies indicate that farmworkers' homes have higher concentrations of pesticides in house dust compared to other homes in the same community [Simcox et al., 1995; Lu et al., 2000]. The levels of pesticide metabolites in children of farmworkers are significantly higher than in children of non-farmworkers [Lu et al., 2000] and are correlated with the metabolite levels of adult farmworkers in the same household [Curl et al., 2002; Coronado et al., 2006] and with pesticide concentrations in house dust samples [Coronado et al., 2006]. Further evidence is provided by findings of detectable levels of pesticides on farmworkers' work boots, children's hands, vehicle steering wheels, and non-carpeted floors in farmworker households but not reference households [Lu et al., 2000], and direct correlations between the number of farmworkers in a household and concentrations of pesticide residues in house dust [McCauley et al., 2001].

Farmworkers are required by the U.S. Environmental Protection Agency's Worker Protection Standard to undergo pesticide safety training a minimum of every 5 years [United States Environmental Protection Agency, 1992]. The training material covers recommendations put forth by the EPA pertaining to ways in which agricultural workers can reduce their exposure to pesticides and includes behaviors to reduce the take-home pathway and occupational exposures. These recommendations include washing hands before eating, smoking, or using the restroom, wearing protective clothing to minimize skin contact with pesticide residue at work, showering and changing clothes immediately after work, and washing work clothes separately from household laundry and after one use [United States Environmental Protection Agency, 1995]. For agricultural workers who work primarily in the fields and do not handle pesticides directly, protective clothing may include long-sleeved shirts, long pants, work boots, gloves, and a hat. Employers are not mandated to provide protective clothing or equipment to agricultural workers who enter treated areas once the reentry interval (the time immediately following the application of a pesticide during which unprotected workers should not enter a field) has passed [United States Environmental Protection Agency, 1992].

The effectiveness of these behaviors in reducing pesticide exposure has not been evaluated extensively under realworld conditions. A review by Quandt et al. [2006] provides a detailed overview of studies that have investigated predictors of pesticide exposure, including the extent to which taking precautions was associated with reduced exposure. Several studies provide support for reduced dermal exposure associated with the use of gloves, coveralls, outer work shirts, and work pants among farmworkers not working as applicators [Spencer et al., 1995; Gomes et al., 1999; Keifer, 2000; Hernandez-Valero et al., 2001]. Washing clothes containing pesticide residues in hot water, separately from other laundry, and after one use has been shown to reduce contamination substantially and thus subsequent exposure [National Institutes of Occupational Safety and Health, 1995]. Washing hands in the field was found to reduce levels of the pesticide acephate by $96 \%$ on the hands of a small sample of tobacco harvesters [Curwin et al., 2003]. One study suggests that waiting more than $2 \mathrm{hr}$ before changing out of work clothes is associated with higher levels of pesticide residue in house dust [McCauley et al., 2003]; however, another study found no association between specific home protective practices and levels of pesticide metabolites in children of farmworkers [Lu et al., 2000].

Whether farmworkers engage in these practices and the factors that influence their adoption have been the focus of recent investigations. Studies in Oregon, North Carolina, Washington, and California suggest that a considerable proportion of farmworkers, primarily those working in the fields, are not engaging in protective practices [Vaughan, 1993; Arcury et al., 1999; McCauley et al., 2001; Goldman et al., 2004], although the percentages vary across states. Studies in North Carolina suggest that farmworkers' perceived control of their ability to protect themselves from the harmful effects of pesticide exposure is related to their safety practices at work: farmworkers with greater perceived control exhibited greater knowledge about protective behaviors and reported engaging in work-related protective behaviors more often than farmworkers with lower perceived control [Austin et al., 2001; Arcury et al., 2002]. In addition to perceived control, studies have found that issues of discomfort, financial pressures, and training history may also influence safety practices at work [Vaughan, 1993; Elmore and Arcury, 2001].

Farmworkers' homes may be a place where they have greater control to protect themselves and household members from pesticide exposure. Few studies have investigated predictors of safety practices at home. Thompson et al. [2003] noted that farmworkers involved in the direct handling of pesticides were more likely to engage in certain protective practices compared to other farmworkers. Other studies have found crowded households to be associated with lower overall adoption of safety practices [Goldman et al., 2004; Rao et al., 2006].

Identifying the factors that influence safety practices may aid the design of health promotion efforts that encourage farmworkers' adoption of these behaviors. The Health Belief Model [Rosenstock, 1990], a value-expectancy model that predicts behavior from perceived threat to a disease combined with barriers and benefits of recommended action, may facilitate understanding of the cognitive factors important to performing these behaviors. Recognizing that 
factors at both the individual level and beyond the individual level are likely to relate to pesticide safety behaviors, we adapted the Health Belief Model and incorporated additional factors to examine the importance of beliefs, occupational characteristics, and an attribute of the worksite to farmworkers' engagement in pesticide safety practices.

\section{MATERIALS AND METHODS}

\section{Setting}

This study uses baseline data from a communityrandomized intervention trial designed to raise awareness about pesticide exposure in agricultural communities and reduce the take-home pathway of pesticide exposure in farmworker households through a community-based participatory research approach. Thompson et al. [2003] describe the setting, study design, survey procedures, and participants in detail. Briefly, the study took place in the Lower Yakima Valley in Eastern Washington, an area comprised of many small agricultural communities in Yakima county, where the 2004 U.S. Census estimated the percentage of Hispanics to be $39 \%$ [U.S. Bureau of the Census, 2004]. Many Hispanics in the area are involved in the harvesting, pruning, and thinning of crops.

\section{Study Design}

Households for the baseline sample were first identified through a concurrent population-based study that involved 20 communities in the Valley and oversampled Hispanics by randomly selecting larger percentages of the households from census blocks with a high proportion of Hispanic residents [Thompson et al., 2002]. The questionnaire for that study inquired about agricultural work in the past 12 months. Respondents who answered affirmatively were later screened for agricultural work in the previous 3 months, and those meeting eligibility criteria were recruited for this study. One community did not have any agricultural workers and was excluded. Three communities contained only a small number of farmworkers, so additional farmworker households were identified by sampling additional homes in the remaining sixteen communities and recruiting households in eight labor camps. Of 1,264 households identified through these strategies, 651 were ineligible because they did not have farmworkers in the household $(n=627)$ or could not be reached $(n=24)$. Approximately $93 \%$ (571) of the remaining 613 households agreed to participate (Fig. 1). Of the 571 farmworkers enrolled, we excluded from the analysis 4 who were not Hispanic or non-Hispanic white and 13 who did not work in agriculture in the past 3 months. Our final sample included 554 respondents from 19 communities and 8 labor camps. The number of respondents from each community/ labor camp ranged from 2 to 48 , with a mean of 21 .

\section{Survey Procedures}

Locally hired and trained bilingual staff obtained informed consent and conducted in-person interviews with adult farmworkers in the summer of 1999. The survey instrument contained 73 items and inquired about agricultural tasks, general pesticide exposure in job tasks, personal perceived health effects of exposure, farmworker protective practices at work, employer practices at work, family

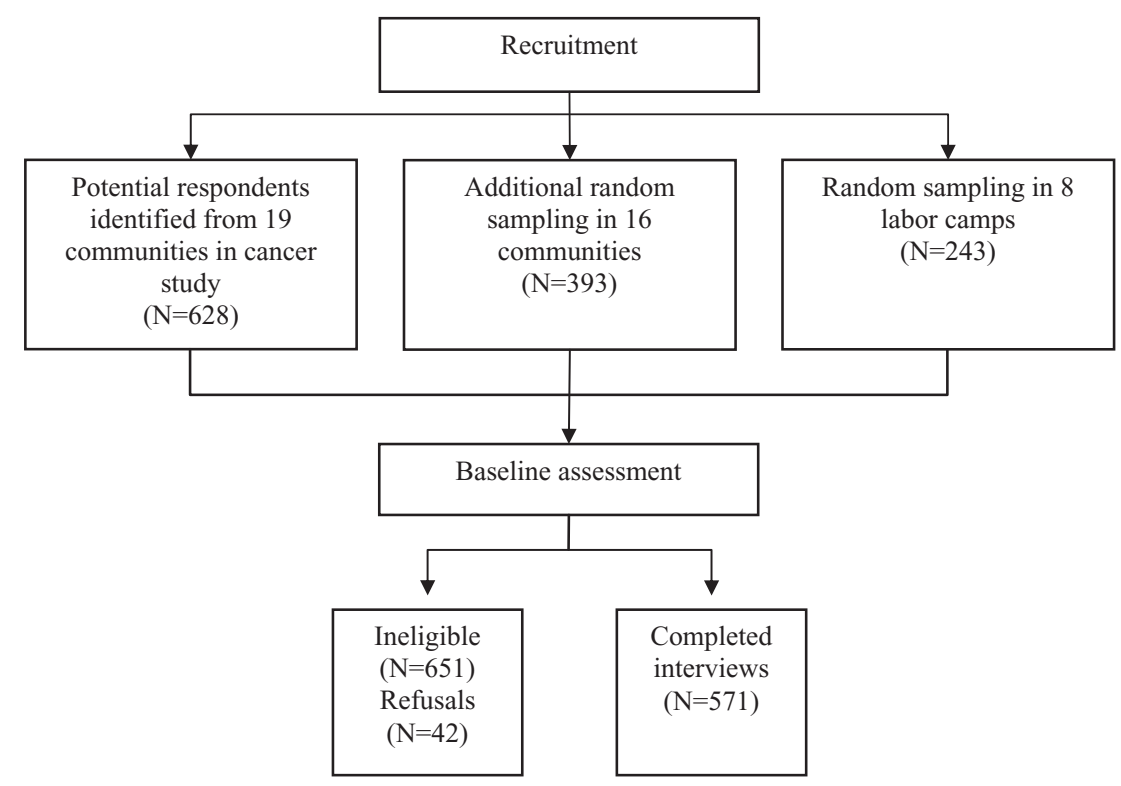

FIGURE 1. Study design. 
protective practices, and demographics. Study design and data collection procedures were approved by the Human Subjects Committee at the University of Washington and the Institutional Review Board at the Fred Hutchinson Cancer Research Center.

\section{Measures}

We evaluated farmworkers' reported safety practices to reduce both occupational pesticide exposure and the takehome pathway of exposure with questions adapted from a study conducted by the National Institute for Occupational Safety and Health in conjunction with community and migrant health organizations [Cameron et al., 2006]. These measures have not been validated. For work protective practices, respondents were asked how often in the previous 3 months when not working as an applicator or sprayer they wore the following personal protective equipment (PPE): protective boots, gloves, a hat, and protective lenses or goggles. For home protective practices, respondents were asked if they washed their hands immediately after work, removed their boots or work shoes before entering the home, washed work clothes separately from household laundry, and held young children while wearing work clothes. Response categories were "always, usually, sometimes, rarely, or never." With the exception of holding young children while in work clothes, we collapsed these categories to "always/ usually" and "sometimes/rarely/never" to allow comparisons in the analysis between farmworkers who engaged in these practices consistently with those who did not. For the variable that assessed whether respondents held young children while in work clothes, we collapsed the responses to "always/usually/sometimes" and "rarely/never." Respondents were also asked how soon after returning home from work they removed their work clothes and showered or bathed ("less than $1 \mathrm{hr}, 1-2 \mathrm{hr}$, more than $2 \mathrm{hr}$ "), and after how many wearings they washed their work clothes ("after wearing one time, after wearing two times, after wearing three or more times"). We collapsed these variables into "less than $1 \mathrm{hr}$ " versus " 1 or more hours" and "after wearing one time" versus "wearing two or more times," respectively, for the analyses. We then created separate indices for work and home protective practices by adding one point for each behavior performed. For the home protective practices we constructed two indices-one that excluded whether farmworkers reported holding young children while in their work clothes, and one that included this variable. This was necessary because the question pertained only to respondents with young children in their house holds. The resulting indices included a 4-point scale for work protective practices, and a 6- and 7-point scale for home protective practices.

We assessed farmworkers' beliefs around pesticide exposure and protective practices with a set of 11 statements created with the project's community advisory board following focus groups with farmworkers. These statements sought to address farmworkers' perceived health threat of pesticide exposure, perceived benefits to performing protective practices, and perceived barriers to performing these behaviors. Response categories included "strongly agree, agree, disagree, and strongly disagree." Because a number of these beliefs were correlated with one another, and we were interested in the importance of the underlying constructs to pesticide safety practices, we performed a factor analysis using the principal components factor method in Stata 8.0 to extract a set of factors to include in the multivariate analyses [Dixon, 1993; StataCorp, 2003]. We examined 9 of the 11 beliefs in the factor analysis; 2 beliefs exhibited poor reliability and were analyzed as individual variables. We retained three factors based on their eigenvalues and conceptual relationships and rotated the factors with a varimax (orthogonal) rotation. Item loadings for each factor are presented in Table I. We labeled the factors perceived health

TABLE I. Principal Factors and Varimax-Rotated Item Loadings for Beliefs Regarding Farm Chemicals

\begin{tabular}{|c|c|c|c|}
\hline Beliefs & $\begin{array}{l}\text { Perceived } \\
\text { health } \\
\text { threat }\end{array}$ & $\begin{array}{l}\text { Perceived } \\
\text { benefits }\end{array}$ & $\begin{array}{c}\text { Perceived } \\
\text { organizational } \\
\text { barriers }\end{array}$ \\
\hline $\begin{array}{l}\text { Chemicals such as pesticides that } \\
\text { are used in the fields cause } \\
\text { harmful effects in workers }\end{array}$ & 0.79 & 0.17 & -0.18 \\
\hline $\begin{array}{l}\text { Chemicals used in the fields cause } \\
\text { harmful health effects in the } \\
\text { children of agricultural workers }\end{array}$ & 0.84 & 0.06 & -0.17 \\
\hline $\begin{array}{l}\text { I am concerned about coming in } \\
\text { contact with farm chemicals } \\
\text { while I am working }\end{array}$ & 0.81 & 0.09 & -0.14 \\
\hline $\begin{array}{l}\text { I am concerned about coming in } \\
\text { contact with farm chemicals } \\
\text { that drift over from nearby } \\
\text { fields, while I am at home }\end{array}$ & 0.82 & 0.17 & -0.08 \\
\hline $\begin{array}{l}\text { Protecting myself from farm } \\
\text { chemicals will allow me to } \\
\text { live a healthier life }\end{array}$ & 0.30 & 0.77 & -0.11 \\
\hline $\begin{array}{l}\text { It is important to protect my } \\
\text { children from farm chemicals }\end{array}$ & 0.34 & 0.66 & 0.18 \\
\hline $\begin{array}{l}\text { Protective clothing protects } \\
\text { me from becoming exposed } \\
\text { to farm chemicals }\end{array}$ & -0.09 & 0.77 & 0.06 \\
\hline $\begin{array}{l}\text { If I asked to be protected from } \\
\text { farm chemicals, I might lose } \\
\text { my job }\end{array}$ & -0.18 & 0.04 & 0.83 \\
\hline $\begin{array}{l}\text { If I complained about coming in } \\
\text { contact with farm chemicals, } \\
\text { nothing would be done }\end{array}$ & -0.16 & 0.01 & 0.83 \\
\hline
\end{tabular}


threat, perceived benefits of protective practices, and perceived organizational barriers to protective practices. Cronbach's alpha was $0.86,0.65$, and 0.64 for the three factors, respectively. For ease of interpretation, we scaled the factors according to their interquartile range, such that a oneunit increase in value represents an increase from the 25th percentile to the 75 th percentile. For perceived health threat and perceived benefits, a higher factor value indicated greater endorsement. For perceived organizational barriers, a higher factor value indicated greater disagreement.

Occupational characteristics included respondents' job task in the past 3 months (handler of pesticides/non-handler), receipt of pesticide safety training in the previous 5 years (yes/no), and perceived skin contact with pesticides in the previous 3 months ("almost every day, once in a while, rarely, never"). For the analysis, we collapsed skin contact with pesticides to "almost every day/once in a while" and "rarely/ never." Workers who reported mixing, handling, or applying pesticides in the past 3 months were considered pesticide handlers. Because job activities were not mutually exclusive, many pesticide handlers also performed field work during the same time period. Whether employers provided protective clothing or equipment in the past 3 months (yes/no) represented an attribute of the worksite.

\section{Data Analysis}

The nesting of farmworkers within communities raises an important methodological issue-responses from farmworkers living in the same communities may be correlated as a result of differences in community norms, resources, facilities, etc. To deal with this, we treated community-level effects as random effects for all statistical tests. We first conducted bivariate analyses. To assess differences by ethnicity in the endorsement of beliefs, we compared percentages of Hispanic and non-Hispanic White farmworkers who agreed or strongly agreed with the 11 belief statements. To evaluate the statistical significance of these differences, we performed a mixed-effects logistic regression analysis with ethnicity as the independent variable and the beliefs as the dependent variables using PROC GLIMMIX in SAS 9.1 [SAS Institute Inc., 2004]. Ethnicity was treated as a fixed effect. To determine the importance of farmworkers' beliefs, occupational characteristics, and demographics to work and home protective practices, we used the work and home behavior indices as our outcome variables for all analyses. We used the indices rather than the individual behaviors for two reasons: (1) treating each behavior as an outcome would require a large number of tests and increase the likelihood that some significant results were due to chance alone; and (2) conceptually, we find the indices more meaningful as an overall representation of protective practices.

Treating the indices as continuous variables, we constructed mixed-effects linear regression models using
PROC MIXED in SAS 9.1 [SAS Institute Inc., 2004]. We first estimated unadjusted regression coefficients with the following independent variables considered individually in separate models as fixed effects: gender, ethnicity, whether respondents lived in a labor camp (yes/no), the three belief factors, the two individual beliefs (protective equipment is uncomfortable; protective equipment slows down work), receipt of training in the past 5 years, and in the past 3 months whether employers provided protective clothing and equipment, whether farmworkers handled pesticides directly, and farmworkers' perceived skin contact with pesticides. We examined each of these predictors in our multivariate model for work protective practices while also adjusting for age, education (less than 5th grade, 5th-8th grade, some high school, high school graduate or higher), and years in agriculture. Our multivariate model for home protective practices was similar; however, we excluded whether employers provided PPE and negative beliefs about PPE, and we added as covariates marital status (married/not married) and having children under 18 in the home (yes/no). We identified these variables a priori as potential confounders of the relationships between the independent variables and the behavior indices. We also evaluated whether the relationships between the belief factors and performing protective practices varied by ethnicity or labor camp status. None of the interaction terms was statistically significant, so we did not include them in the final models. We examined plots of residuals against predicted values and quantile-quantile plots for both the fixed and random error to ensure that the assumptions of linear mixed models were met.

\section{Missing Data}

Our sample was missing age in approximately $15 \%$ of respondents because some of the interviewers failed to collect respondents' age. Respondents with missing age were significantly more likely to be Hispanic $(P=0.01)$, report fewer years of education $(P=0.05)$, and believe that they would lose their job if asked to be protected from farm chemicals $(P=0.005)$ compared to respondents with complete age data. Several belief variables were also missing responses. Of the eleven beliefs examined, four were missing between $1 \%$ and $5 \%$, and two were missing approximately $7 \%$ of observations. The factor analysis procedure uses only complete data; thus, performing a complete case analysis would result in a cumulative loss of approximately $18 \%$ of responses due to missing belief data alone. Respondents who had incomplete belief data were significantly more likely to be Hispanic $(P=0.002)$ and marginally significantly more likely to be female $(P=0.07)$. Because of the potential for systematic bias and loss of power with a complete case analysis, we used multiple imputation [Rubin, 1987; Raghunathan, 2004]. This approach relies on the relaxed assumption that missingness is a function of observed 
variables only, rather than assuming that missingness is independent of both observed and unobserved data [Little and Rubin, 1987]. First, we generated a set of five plausible values for each missing observation by regressing the variable with missing responses on specified predictors using a bootstrap sample with the program ICE in Stata 8.0, which performs multiple imputation with chained equations [Royston, 2004, 2005]. We selected predictors according to the following criteria: inclusion in the analytic model, a significant association with missingness, and a significant correlation with the variable with missing values [Van Buuren, 1999]. Using PROC MIANALYZE in SAS 9.1 [SAS Institute Inc., 2004; Yuan, 2000], we performed the mixed model regression analyses described above on each of the five datasets and obtained estimated coefficients and standard errors that incorporated within- and betweenimputation variability [Rubin 1987].

\section{RESULTS}

Table II presents the demographic and occupational characteristics of the 554 farmworkers included in the analysis. Overall, the vast majority of respondents were Hispanic (89\%), and nearly three-quarters were male. The overwhelming majority (91\%) lived in the Yakima Valley year-round. We observed notable differences in the demographic and occupational characteristics of Hispanics compared with non-Hispanic Whites. As reported previously for these data [Thompson et al., 2003], Hispanic farmworkers were younger, reported fewer years of education, reported a lower annual household income, and were less likely to be male and work as a pesticide handler than non-Hispanic White farmworkers. In addition, we found that a greater percentage of non-Hispanic Whites reported being trained in the last 5 years (65\% vs. 24\%), being provided with PPE at

TABLE II. Demographic and Occupational Characteristics of 554 Farmworkers in Eastern Washington, Overall and by Ethnicity

\begin{tabular}{|c|c|c|c|c|c|c|}
\hline \multirow[b]{2}{*}{ Characteristic } & \multicolumn{2}{|c|}{ Total $(n=554)$} & \multicolumn{2}{|c|}{ Hispanic $(n=494)$} & \multicolumn{2}{|c|}{ Non-Hispanic White $(\mathbf{n}=60)$} \\
\hline & $\mathrm{n}$ & $\%$ & $\mathrm{n}$ & $\%$ & $\mathbf{n}$ & $\%$ \\
\hline \multicolumn{7}{|l|}{ Age (years) } \\
\hline $18-24$ & 70 & 12.7 & 65 & 13.2 & 5 & 8.3 \\
\hline $25-34$ & 178 & 32.1 & 172 & 34.8 & 6 & 10.0 \\
\hline $35-49$ & 195 & 35.2 & 176 & 35.6 & 19 & 31.7 \\
\hline $50+$ & 111 & 20.0 & 81 & 16.4 & 30 & 50.0 \\
\hline \multicolumn{7}{|l|}{ Gender } \\
\hline Male & 407 & 73.5 & 355 & 71.9 & 52 & 86.7 \\
\hline \multicolumn{7}{|l|}{ Education } \\
\hline 4th grade or less & 183 & 33.0 & 182 & 36.8 & 1 & 1.7 \\
\hline 5th-8th grade & 188 & 33.9 & 184 & 37.3 & 4 & 6.7 \\
\hline 9th-12th grade & 116 & 20.9 & 104 & 21.1 & 12 & 20.0 \\
\hline High school graduate or higher & 67 & 12.1 & 24 & 4.9 & 43 & 71.7 \\
\hline \multicolumn{7}{|l|}{ Annual household income $(n=531)$} \\
\hline$\leq \$ 15,000$ & 274 & 51.6 & 266 & 55.2 & 8 & 16.3 \\
\hline$\$ 15,001-\$ 25,000$ & 164 & 30.9 & 160 & 33.2 & 4 & 8.2 \\
\hline$>\$ 25,000$ & 93 & 17.5 & 56 & 11.6 & 37 & 75.5 \\
\hline \multicolumn{7}{|l|}{ Marital status } \\
\hline Married, living as married & 451 & 81.4 & 399 & 80.8 & 52 & 86.7 \\
\hline \multicolumn{7}{|l|}{ Years in agriculture $(n=534)$} \\
\hline Less than 5 & 89 & 16.7 & 87 & 18.3 & 2 & 3.4 \\
\hline $5-9$ & 111 & 20.8 & 105 & 22.1 & 6 & 10.2 \\
\hline $10-19$ & 154 & 28.8 & 144 & 30.3 & 10 & 17.0 \\
\hline More than 20 & 180 & 33.7 & 139 & 29.3 & 41 & 69.5 \\
\hline Live in Yakima Valley year-round & 503 & 90.8 & 445 & 90.1 & 58 & 96.7 \\
\hline Live in a labor camp & 118 & 21.3 & 116 & 23.5 & 2 & 3.3 \\
\hline Handled pesticides in past 3 months & 171 & 30.9 & 128 & 25.9 & 43 & 71.7 \\
\hline Received pesticide safety training within past 5 years & 158 & 28.5 & 119 & 24.1 & 39 & 65.0 \\
\hline Employer provided PPE in past 3 months & 232 & 41.8 & 182 & 36.8 & 50 & 83.3 \\
\hline Perceived regular skin contact with pesticides in past 3 months & 297 & 53.6 & 275 & 55.7 & 22 & 36.7 \\
\hline
\end{tabular}


work (83\% vs. 37\%), and reported longer tenures in agriculture compared to Hispanic farmworkers. Hispanic farmworkers were also more likely to perceive regular skin contact with pesticides in the past 3 months.

Farmworkers' beliefs around pesticide exposure and protective practices are shown in Table III. Overall, we found strong endorsement of beliefs related to perceived health threat of pesticide exposure and perceived benefits of protective practices. Hispanics were significantly more likely than nonHispanic Whites to be concerned about pesticide exposure and its harmful effects for themselves and their children, to report that protective equipment slows down their work, and to perceive organizational barriers at work to protecting oneself from pesticides. Notably, only $34 \%$ of non-Hispanic Whites agreed that chemicals used in the fields cause harmful effects in the children of agricultural workers compared to 95\% of Hispanics $(P<0.001)$. We present the frequencies and percentages of farmworkers' reported work and home protective practices in the past 3 months in Table IV. For work protective practices, percentages of consistent use ranged from $23 \%$ for protective lenses or goggles to $82 \%$ for wearing a hat. With the exception of wearing a hat, protective clothing and equipment was reported by fewer than half of respondents. Of four total behaviors, the mean number performed was 1.8. In general, higher proportions of farmworkers engaged in home protective practices. Just under $60 \%$ reported always or usually washing their hands immediately after work, removing their boots or shoes prior to entering the home, and changing out of work clothes within $1 \mathrm{hr}$ of arriving home. Nearly two-thirds reported washing their work clothes after one wearing and reported rarely or never holding their children while in their work clothes. Farmworkers were most likely to report always or usually washing work clothes separately from household laundry $(83 \%)$ and least likely to report showering within $1 \mathrm{hr}$ of arriving home (47\%). Of six total behaviors, excluding whether farmworkers refrained

TABLE III. Percentages of Farmworkers who Reported That They "Strongly Agreed/Agreed" With the Following statements ${ }^{\mathrm{a}}$

\begin{tabular}{|c|c|c|c|c|c|c|}
\hline \multirow[b]{2}{*}{ Belief } & \multicolumn{2}{|c|}{ Total $(n=554)$} & \multicolumn{2}{|c|}{ Hispanic $(n=494)$} & \multicolumn{2}{|c|}{ Non-Hispanic White $(n=60)$} \\
\hline & $\mathbf{n}$ & $\%$ & $\mathbf{n}$ & $\%$ & $\mathbf{n}$ & $\%$ \\
\hline \multicolumn{7}{|l|}{ Perceived health threat } \\
\hline $\begin{array}{l}\text { Chemicals such as pesticides that are used in the fields cause } \\
\text { harmful effects in workers }\end{array}$ & 509 & 91.9 & 482 & $97.6^{\star \star \star}$ & 27 & 45.0 \\
\hline $\begin{array}{l}\text { Chemicals used in the fields cause harmful health effects in } \\
\text { the children of agricultural workers }\end{array}$ & 491 & 88.6 & 471 & $95.3^{\star \star \star}$ & 20 & 34.0 \\
\hline $\begin{array}{l}\text { Iam concerned about coming in contact with farm chemicals while } \\
\text { Iam working }\end{array}$ & 469 & 84.7 & 445 & $90.0^{\star \star \star}$ & 24 & 41.0 \\
\hline $\begin{array}{l}\text { I am concerned about coming in contact with farm chemicals that } \\
\text { drift over from nearby fields, while I am at home }\end{array}$ & 482 & 87.5 & 454 & $91.9^{\star \star \star}$ & 28 & 46.7 \\
\hline \multicolumn{7}{|l|}{ Perceived benefits } \\
\hline $\begin{array}{l}\text { Protecting myself from farm chemicals will allow me to live a } \\
\text { healthier life }\end{array}$ & 537 & 96.9 & 484 & $97.9^{\star \star}$ & 53 & 88.3 \\
\hline It is important to protect my children from farm chemicals & 551 & 99.5 & 492 & 99.6 & 59 & 98.3 \\
\hline $\begin{array}{l}\text { Protective clothing protects me from becoming exposed to } \\
\text { farm chemicals }\end{array}$ & 518 & 93.5 & 462 & 93.5 & 56 & 93.3 \\
\hline \multicolumn{7}{|l|}{ Perceived organizational barriers } \\
\hline If I asked to be protected from farm chemicals, I might lose my job & 206 & 37.2 & 202 & $40.9^{\star \star}$ & 4 & 6.7 \\
\hline $\begin{array}{l}\text { If I complained about coming in contact with farm chemicals, } \\
\text { nothing would be done }\end{array}$ & 250 & 45.1 & 245 & $49.6^{\star \star \star}$ & 5 & 8.3 \\
\hline \multicolumn{7}{|l|}{ Individual beliefs ${ }^{\mathrm{b}}$} \\
\hline $\begin{array}{l}\text { Wearing equipment to protect me from contact with farm } \\
\text { chemicals is uncomfortable }\end{array}$ & 474 & 85.6 & 422 & 85.4 & 52 & 86.7 \\
\hline $\begin{array}{l}\text { Wearing equipment to protect me from contact with farm } \\
\text { chemicals slows me down in my work }\end{array}$ & 448 & 80.9 & 415 & $84.0^{\star \star \star}$ & 33 & 55.0 \\
\hline
\end{tabular}

The statistical significance of differences was estimated using Generalized Linear Mixed Models.

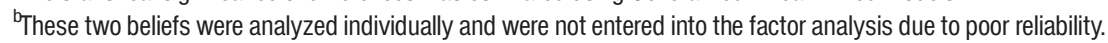

${ }^{\star \star} P<0.01$ for differences in belief endorsement among Hispanics and non-Hispanic Whites.

${ }^{\star \star \star} P<0.001$ for differences in belief endorsement among Hispanics and non-Hispanic Whites. 
TABLE IV. Farmworkers' Reported Practices in the Past 3 Months to Reduce 0ccupational Pesticide Exposure and the Take-Home Pathway ( $n=554)$

\begin{tabular}{|c|c|c|c|c|c|c|}
\hline \multirow[b]{2}{*}{ Behavior } & \multicolumn{2}{|c|}{ Always/usually } & \multicolumn{2}{|c|}{ Sometimes } & \multicolumn{2}{|c|}{ Rarely/never } \\
\hline & $\mathbf{n}$ & $\%$ & $\mathbf{n}$ & $\%$ & $\mathbf{n}$ & $\%$ \\
\hline \multicolumn{7}{|l|}{ Protective gear at work } \\
\hline Protective boots & 228 & 41.2 & 78 & 14.1 & 248 & 44.8 \\
\hline Gloves & 213 & 38.4 & 146 & 26.4 & 195 & 35.2 \\
\hline Hat & 455 & 82.1 & 21 & 3.8 & 78 & 14.1 \\
\hline Protective lenses & 126 & 22.7 & 111 & 20.0 & 317 & 57.2 \\
\hline \multicolumn{7}{|l|}{ Protective practices at home } \\
\hline Wash hands right after work & 322 & 58.1 & 83 & 15.0 & 149 & 26.9 \\
\hline Take off shoes/boots before entering home & 314 & 56.7 & 74 & 13.3 & 166 & 30.0 \\
\hline Wash work clothes separately from household laundry & 459 & 82.9 & 28 & 5.0 & 67 & 12.1 \\
\hline \multirow[t]{2}{*}{ Hold young children while wearing work clothes $(n=460)$} & 87 & 18.9 & 85 & 18.5 & 288 & 62.6 \\
\hline & \multicolumn{2}{|c|}{ Less than $1 \mathrm{hr}$} & \multicolumn{2}{|c|}{$1-2 \mathrm{hr}$} & \multicolumn{2}{|c|}{ More than $2 \mathrm{hr}$} \\
\hline How long after work waited to change out of work clothes & 314 & 56.7 & 147 & 26.5 & 93 & 16.8 \\
\hline \multirow[t]{2}{*}{ How long after work waited to shower } & 262 & 47.3 & 222 & 40.1 & 70 & 12.6 \\
\hline & \multicolumn{2}{|c|}{ After wearing once } & \multicolumn{2}{|c|}{ After wearing twice } & \multicolumn{2}{|c|}{$\begin{array}{c}\text { After wearing three or } \\
\text { more times }\end{array}$} \\
\hline How often wash work clothes & 369 & 66.6 & 149 & 26.9 & 36 & 6.5 \\
\hline
\end{tabular}

from holding their children, the mean number practiced was 3.7. Including this variable, the mean number reported was 4.5 .

In the bivariate analyses (Table V), we observed a number of statistically significant relationships between the independent variables and the indices for protective practices. Believing that protective equipment slows one down and perceiving organizational barriers to protecting oneself were associated with wearing fewer protective items at work. Receiving PPE from employers, working as a handler of pesticides, and having received safety training in the past 5 years all predicted greater use of PPE at work. Reporting regular skin exposure to pesticides was associated negatively with work practices. We observed similar relationships between training history, handling pesticides, perceived exposure, and home protective practices. Living in a labor camp was positively associated with the number of home practices performed. No other demographic characteristics were associated with home practices, despite the considerable variation in beliefs between Hispanics and nonHispanic Whites. Results were similar for the home behavior index that included whether farmworkers refrained from holding their children while in their work clothes with the exception that perceiving organizational barriers to protecting oneself was not significantly associated with the number of protective practices (data not shown).

In the multivariate models, many associations that were significant in the bivariate analyses were attenuated after adjustment for confounding. As shown in Table VI, working as a handler of pesticides and the belief factors were no longer significant predictors of work practices. Rather, respondents who received PPE from their employers reported significantly greater use of protective clothing than those who did not receive PPE, and respondents who perceived regular skin exposure to pesticides engaged in significantly fewer work practices than respondents who perceived infrequent exposure. Receipt of training was also associated significantly with increased use of PPE, although just barely $(P=0.05)$. For home protective practices, men took significantly fewer precautions than women after adjusting for other variables. Perceiving organizational barriers to protecting oneself from pesticides at work was associated with engaging in fewer home practices. In addition, farmworkers who lived in labor camps, received pesticide safety training in the past 5 years, and who handled pesticides took more precautions at home than farmworkers who did not live in labor camps, had not been trained, and non-handlers of pesticides, respectively. Although the estimates for the home behavior index that included whether farmworkers refrained from holding their children while in their work clothes were similar, there were some differences. Perceiving organizational barriers to protecting oneself at home was not associated with the number of precautions taken $(\beta=-0.24 ; 95 \% \mathrm{CI}=-0.55$, $0.07)$, whereas the inverse relationship between perceiving regular skin contact with pesticides and taking precautions was significant for this index $(\beta=-0.45 ; 95 \% \mathrm{CI}=-0.77$, $-0.13)$.

\section{DISCUSSION}

In this study we sought to characterize factors related to work and home pesticide safety practices in a large sample of 
TABLE V. Unadjusted regression coefficients ${ }^{\mathrm{a}}$ for the work and home behavior indices of pesticide safety practices

\begin{tabular}{|c|c|c|c|c|}
\hline & \multicolumn{2}{|c|}{ Work behavior index } & \multicolumn{2}{|c|}{ Home behavior index } \\
\hline & $\boldsymbol{\beta}$ & $95 \% \mathrm{CI}$ & $\boldsymbol{\beta}$ & $95 \% \mathrm{CI}$ \\
\hline \multicolumn{5}{|l|}{ Demographics } \\
\hline \multicolumn{5}{|l|}{ Gender } \\
\hline Female & Ref & & Ref & \\
\hline Male & $0.36^{\star \star \star}$ & $0.15,0.57$ & -0.13 & $-0.43,0.18$ \\
\hline \multicolumn{5}{|l|}{ Ethnicity } \\
\hline Non-Hispanic White & Ref & & Ref & \\
\hline Hispanic & -0.24 & $-0.54,0.06$ & -0.09 & $-0.53,0.34$ \\
\hline \multicolumn{5}{|l|}{ Living in a labor camp } \\
\hline No & Ref & & Ref & \\
\hline Yes & -0.01 & $-0.30,0.29$ & $0.38^{*}$ & $0.01,0.76$ \\
\hline \multicolumn{5}{|l|}{ Belief factors } \\
\hline Perceived health threat & -0.02 & $-0.05,0.01$ & 0.01 & $-0.04,0.05$ \\
\hline Perceived benefits & 0.02 & $-0.00,0.04$ & 0.01 & $-0.02,0.04$ \\
\hline Perceived organizational barriers & $-0.20^{\star}$ & $-0.36,-0.04$ & $-0.32^{\star \star}$ & $-0.55,-0.09$ \\
\hline \multicolumn{5}{|l|}{ Individual beliefs } \\
\hline Protective equipment is uncomfortable & -0.24 & $-0.50,0.03$ & $\mathrm{~N} / \mathrm{A}$ & \\
\hline Protective equipment slows down work & $-0.36^{\star \star}$ & $-0.60,-0.12$ & N/A & \\
\hline \multicolumn{5}{|l|}{ Attribute of worksite } \\
\hline \multicolumn{5}{|l|}{ Employer-provided PPE } \\
\hline No & Ref & & $\mathrm{N} / \mathrm{A}$ & \\
\hline Yes & $0.87^{\star \star \star}$ & $0.69,1.05$ & $\mathrm{~N} / \mathrm{A}$ & \\
\hline \multicolumn{5}{|l|}{ Occupational characteristics } \\
\hline \multicolumn{5}{|l|}{ Handler of pesticides } \\
\hline No & Ref & & Ref & \\
\hline Yes & $0.68^{\star \star \star}$ & $0.48,0.87$ & $0.62^{\star \star \star}$ & $0.34,0.91$ \\
\hline \multicolumn{5}{|l|}{ Perceived skin contact with pesticides } \\
\hline Rarely/never & Ref & & Ref & \\
\hline Every day/once in a while & $-0.24^{\star}$ & $-0.43,-0.06$ & $-0.31^{\star}$ & $-0.57,-0.04$ \\
\hline \multicolumn{5}{|l|}{ Pesticide safety training in past 5 years } \\
\hline No & Ref & & Ref & \\
\hline Yes & $0.60^{\star \star \star}$ & $0.39,0.80$ & $0.56^{\star \star \star}$ & $0.27,0.85$ \\
\hline
\end{tabular}

${ }^{\mathrm{a}}$ Regression coefficients were estimated with Linear Mixed Models.

${ }^{*} P<0.05$.

${ }^{\star \star} P<0.01$.

${ }^{\star * \star} P<0.001$.

farmworkers. We examined individual-level factors, such as beliefs, occupational characteristics, and demographics; interpersonal factors, namely perceived organizational barriers to protecting oneself from pesticide exposure; and an attribute of respondents' worksite, employers' provision of protective clothing and equipment.

We observed striking differences between Hispanics and non-Hispanic Whites in their endorsement of beliefs related to pesticide exposure. Specifically, non-Hispanic Whites were significantly less likely than Hispanics to express concern about being exposed to pesticides, to view pesticides as harmful, to perceive organizational barriers to protecting oneself from pesticides, and to believe that PPE slows down work. Why the majority of non-Hispanic Whites did not view pesticides as a health threat to workers or their children is unclear. Although it was beyond the scope of this paper to identify predictors of each belief, the variation by ethnicity in demographic and occupational characteristics may have contributed to some of the observed differences in beliefs. For example, non-Hispanic Whites' greater likelihood of being provided PPE, receiving training in pesticide safety, perceiving less frequent skin contact with pesticides, and working as a handler of pesticides suggests that the context of their work and the specific tasks performed may have been 
TABLE VI. Adjusted Regression Coefficients ${ }^{\mathrm{a}}$ for the Work and Home Behavior Indices of Pesticide Safety Practices

\begin{tabular}{|c|c|c|c|c|}
\hline & \multicolumn{2}{|c|}{ Work behavior index ${ }^{b}$} & \multicolumn{2}{|c|}{ Home behavior index ${ }^{c}$} \\
\hline & $\beta$ & $95 \% \mathrm{CI}$ & $\boldsymbol{\beta}$ & $95 \% \mathrm{CI}$ \\
\hline \multicolumn{5}{|l|}{ Demographics } \\
\hline \multicolumn{5}{|l|}{ Gender } \\
\hline Female & Ref & & Ref & \\
\hline Male & 0.06 & $-0.16,0.28$ & $-0.45^{\star \star}$ & $-0.78,-0.12$ \\
\hline \multicolumn{5}{|l|}{ Ethnicity } \\
\hline Non-Hispanic White & Ref & & Ref & \\
\hline Hispanic & 0.21 & $-0.22,0.64$ & 0.40 & $-0.25,1.04$ \\
\hline \multicolumn{5}{|l|}{ Living in labor camp } \\
\hline No & Ref & & Ref & \\
\hline Yes & 0.04 & $-0.18,0.26$ & $0.40^{*}$ & $0.07,0.72$ \\
\hline \multicolumn{5}{|l|}{ Belief factors } \\
\hline Perceived health threat & 0.02 & $-0.02,0.06$ & 0.00 & $-0.05,0.05$ \\
\hline Perceived benefits & 0.01 & $-0.01,0.03$ & 0.01 & $-0.02,0.03$ \\
\hline Perceived organizational barriers & -0.03 & $-0.20,0.14$ & $-0.29^{\star}$ & $-0.54,-0.03$ \\
\hline \multicolumn{5}{|l|}{ Individual beliefs } \\
\hline Protective equipment is uncomfortable & -0.13 & $-0.40,0.13$ & $\mathrm{~N} / \mathrm{A}$ & \\
\hline Protective equipment slows down work & -0.21 & $-0.47,0.04$ & $\mathrm{~N} / \mathrm{A}$ & \\
\hline \multicolumn{5}{|l|}{ Attribute of worksite } \\
\hline \multicolumn{5}{|l|}{ Employer-provided PPE } \\
\hline No & Ref & & $\mathrm{N} / \mathrm{A}$ & \\
\hline Yes & $0.68^{\star \star \star}$ & $0.46,0.91$ & $\mathrm{~N} / \mathrm{A}$ & \\
\hline \multicolumn{5}{|l|}{ Occupational characteristics } \\
\hline \multicolumn{5}{|l|}{ Perceived skin contact with pesticides } \\
\hline Rarely/never & Ref & & Ref & \\
\hline Every day/once in a while & $-0.24^{\star \star}$ & $-0.42,-0.06$ & -0.25 & $-0.52,0.01$ \\
\hline \multicolumn{5}{|l|}{ Pesticide safety training in past 5 years } \\
\hline No & Ref & & Ref & \\
\hline Yes & $0.23^{+}$ & $0.00,0.45$ & $0.35^{\star}$ & $0.02,0.68$ \\
\hline \multicolumn{5}{|l|}{ Job task past 3 months } \\
\hline Non-handler of pesticides & Ref & & Ref & \\
\hline Handler of pesticides & 0.18 & $-0.07,0.42$ & $0.61^{\star \star \star}$ & $0.27,0.95$ \\
\hline
\end{tabular}

${ }^{\mathrm{a}}$ Regression coefficients were estimated with Linear Mixed Models.

${ }^{\mathrm{b}}$ In addition to the variables listed above, the work behavior index model was adjusted for age, education, and number of years in agriculture.

${ }^{\mathrm{C}}$ In addition to the variables listed above, the home behavior model was adjusted for age, education, marital status, having children in the home, and years in agriculture.

${ }^{+} P=0.05$.

${ }^{\star} P<0.05$.

${ }^{\star \star} P<0.01$.

${ }^{\star \star \star} P<0.001$.

very different, and may have involved different risks, than work performed by Hispanic farmworkers. This may have been influenced by their higher levels of education, longer tenure in agriculture, ability to speak English, or other factors. These differences may also help to explain why Hispanics were more likely to perceive organizational barriers to protecting oneself from pesticide exposure. Factors related to documentation status or language barriers may be particularly relevant for these beliefs given that they touch on issues of control at work and concerns about job security.

Whether employers provided protective clothing and equipment largely determined farmworkers' use of PPE at work, even after controlling for other relevant factors such as training history, job task, perceived organizational barriers, and negative beliefs about PPE. Although training history remained significantly associated with increased use of PPE, 
the magnitude of the coefficient decreased considerably in the multivariate model. These findings have important implications for efforts that encourage adoption of these behaviors in the field. It suggests that the effectiveness of strategies to improve farmworkers' use of PPE may be limited if these items are not made available. Although gloves, boots, protective lenses, and hats are available at local stores, economic barriers may preclude farmworkers from purchasing them. In focus groups in Washington state, farmworkers expressed frustration with not being provided PPE, and some felt that employers should be required to provide this to all farmworkers, not just those who handle pesticides [Prado and Vanderslice, 2004]. Although we do not know to what extent employers actively encouraged these precautions, it is conceivable that employers' provision of PPE conveyed an attitude that promoted safety or helped to foster positive social norms around safety practices at the worksite.

Consistent with other studies investigating pesticide safety practices at work, farmworkers' use of PPE in this study was influenced strongly by an attribute of the worksite that was largely outside of their control. Although perceived control is defined more broadly than access to protective clothing and equipment, availability of these items is an important component in the context of pesticide safety practices. Studies in North Carolina found that greater perceived control over protecting oneself from pesticide exposure at work was positively associated with taking safety precautions, and that perceived control was a more important predictor of behavior than perceived risk [Austin et al., 2001; Arcury et al., 2002]. Similar findings were observed in a sample of farmworkers in California [Vaughan, 1993]. In contrast with these studies, the belief factor representing perceived organizational barriers to protecting oneself from pesticide exposure was not related significantly to work practices in the multivariate model. Although not a comprehensive measure of control, this factor may be characterized by futility associated with one's efforts to improve protection from chemicals by appealing to persons of authority at work. The significant association observed in the bivariate analysis disappeared in the multivariate model, suggesting that this relationship may be confounded by whether workers received PPE from their employers.

Surprisingly, farmworkers who perceived more frequent skin contact with pesticides performed fewer safety practices at work, and among those with young children, fewer safety practices at home. Because the temporal relationship between these variables is not known, the direction is unclear. It may be that farmworkers perceive less exposure because they use protective clothing and equipment, whereas farmworkers who do not protect themselves perceive more frequent exposure.

Adoption of home protective practices varied by occupational characteristics. As noted previously [Thomp- son et al., 2003], handlers of pesticides were more likely than non-handlers to perform safety practices at home. Since handlers work directly with pesticides, they may be more cognizant of the risks associated with their exposure and more motivated to take precautions. Additionally, handlers are required by the WPS to undergo further training around pesticide safety. In our analysis, we adjusted for differences in receipt of training; however, it is unlikely that this fully accounted for differences in the type of information received and quality of the training. We found that pesticide safety training was related to workers' home protective practices. Incorporating messages about the take-home pathway into mandatory training for all farmworkers may be an effective way to raise awareness of this exposure route and encourage adoption of safety practices. Framing these behaviors within the context of protecting one's family in addition to protecting oneself may improve motivation and ultimately the precautions taken. The finding that fewer than one third of farmworkers reported being trained in the past 5 years, however, is disconcerting, particularly since this is a requirement of the WPS. Unfortunately, these numbers are consistent with other findings [Arcury et al., 1999].

Interestingly, the importance of perceived organizational barriers to protective practices was not restricted to the worksite; farmworkers who strongly endorsed these beliefs were less likely to engage in safety practices at home. The significance of this finding is not clear. It may reflect a sense of resignation regarding one's ability to protect oneself from pesticide exposure in general; farmworkers who feel helpless to protect themselves at work may carry that sentiment home. This may be suggestive of fatalistic beliefs towards preventing harmful effects of pesticide exposure. Fatalism, the perception that individuals have little control over whether they develop or die from a disease, is recognized as an emotion expressed by Hispanics regarding cancer, and particularly among those of Mexican descent [Lantz et al., 1994; Salazar, 1996; Chavez et al., 1997; Ramirez et al., 2000]. Alternatively, some of the recommended behaviors may not be realistic given farmworkers' limited resources and may contribute to a feeling of helplessness. A better understanding of these relationships will aid the development of future interventions.

Finally, the finding that living in a labor camp was significantly associated with taking more precautions to reduce the take-home pathway raises interesting questions about the characteristics of this living environment that may contribute to farmworkers' adoption of pesticide safety practices. Our inclusion of demographic and occupational factors in the multivariate model suggests that the differences we observed in living arrangements are independent of these factors. Because labor camps represent areas with high concentrations of farmworkers, we can speculate that health promotion efforts to raise awareness about pesticide exposure in farmworkers and their families may target labor 
camps over other residential areas. The reasons for this finding are unclear yet warrant additional investigation.

Our analysis has several limitations. First, our data are based on self report and are subject to bias. Second, the survey measures used here have not been validated and thus the psychometric properties are unknown. Third, the belief questions addressing perceived health threat and perceived benefits elicited minimal variation. This likely affected our ability to estimate accurately the relationship between these constructs and safety practices. Fourth, it is not clear whether the behavior variables should have been weighted equally in creating the indices. Although there are qualitative differences between the behaviors within the indices, we had no information on which to base unequal weighting. The technique of adding one point for each behavior has been used previously with farmworkers [Goldman et al., 2004]. Fifth, although we discussed perceived control, we did not measure it directly. Perceived organizational barriers and whether employers provided farmworkers with PPE may reflect issues of control but are unlikely to capture fully the meaning of this construct. Sixth, our imputation of age and several belief variables inevitably introduced a degree of uncertainty into our analysis. Performing a complete case analysis, however, would have resulted in biased estimates as respondents with missing data differed in significant ways from those with complete data. In addition, multiple imputation has been shown to be a robust strategy for accurately estimating missing data. Seventh, the data used in this analysis were collected over 7 years ago and may not represent current perceptions or practices. Finally, the findings reported here may not be representative of migrant or more recently settled populations.

\section{CONCLUSION}

Although we cannot infer causal relationships, findings from this study offer insight regarding possible areas in which to intervene to improve adoption of pesticide safety practices. Perhaps most importantly, our results indicate that many of the factors associated with performing safety practices are beyond the individual level. Implementing changes at the worksite, such as increasing provision of PPE to workers and expanding training to discuss more specifically the take-home pathway, may help to increase regular use of PPE at work and also safety practices at home. Quandt et al. [2001] provide a nice example of engaging the community to develop a training program that is relevant to farmworkers' daily realities, is culturally appropriate, and fosters empowerment. However, as suggested by the low rates of training reported by farmworkers here and in North Carolina [Arcury et al., 1999], sustained changes at the worksite that aim to improve pesticide safety are unlikely in the absence of improved enforcement of existing regulations and the implementation of new ones, such as making PPE available to all farmworkers and by reducing farmworkers' risk of exposure by extending reentry intervals. Addressing these issues and also perceived organizational barriers calls for working with multiple stakeholders, such as representatives from the Farmworkers' Union, the EPA, the Department of Labor and Industries, and farmworker advocacy groups in order to effect widespread change. Community-based participatory research, which engages the community at every stage of the research process, provides a model for mobilizing stakeholders and community members around this issue.

\section{ACKNOWLEDGMENTS}

The authors thank members of the community advisory board, the staff at the community field office, and the participants in this survey for their time and energy in this research, and Dale McLerran for his assistance with data analysis.

\section{REFERENCES}

Arcury TA, Quandt SA, Austin CK, Preisser J, Cabrera LF. 1999. Implementation of EPA's Worker Protection Standard training for agricultural laborers: An evaluation using North Carolina data. Public Health Rep 114:459-468.

Arcury TA, Quandt SA, Russell GB. 2002. Pesticide safety among farmworkers: Perceived risk and perceived control as factors reflecting environmental justice. Environ Health Perspect 110(Suppl 2):233-240.

Austin C, Arcury TA, Quandt SA, Preisser JS, Saavedra RM, Cabrera LF. 2001. Training farmworkers about pesticide safety: Issues of control. J Health Care Poor Underserved 12:236-249.

Cameron L, Lalich N, Bauer S, Booker V, Bogue HO, Samuels S, Steege AL. 2006. Occupational health survey of farm workers by camp health aides. J Agric Saf Health 12:139-153.

Chavez LR, Hubbell FA, Mishra SI, Valdez RB. 1997. The influence of fatalism on self-reported use of Papanicolaou smears. Am J Prev Med $13: 418-424$.

Cordes D, Foster D. 1988. Health hazards of farming. Am Fam Physician 38:233-244.

Coronado GD, Vigoren EM, Thompson B, Griffith WC, Faustman EM. 2006. Organophosphate pesticide exposure and work in pome fruit: Evidence for the take-home pesticide pathway. Environ Health Perspect 114:999-1006.

Curl CL, Fenske RA, Kissel JC, Shirai JH, Moate TF, Griffith W, Coronado G, Thompson B. 2002. Evaluation of take-home organophosphorus pesticide exposure among agricultural workers and their children. Environ Health Perspect 110:A787-A792.

Curwin BD, Hein MJ, Sanderson WT, Nishioka M, Buhler W. 2003. Acephate exposure and decontamination on tobacco harvesters' hands. J Expo Anal Environ Epidemiol 13:203-210.

Dixon JK. 1993. Grouping techniques. In: Munro BH, Page EB, editors Statistical methods for health care research 2 nd edition. Philadelphia J.B. Lippincott Company.

Elmore RC, Arcury TA. 2001. Pesticide exposure beliefs among Latino farmworkers in North Carolina's Christmas tree industry. Am J Ind Med 40:153-160. 
Eskenazi B, Bradman A, Castorina R. 1999. Exposures of children to organophosphate pesticides and their potential adverse health effects. Environ Health Perspect 107:409-419.

Faustman EM, Silbernagel SM, Fenske RA, Burbacher TM, Ponce RA. 2000. Mechanisms underlying Children's susceptibility to environmental toxicants. Environ Health Perspect 108(Suppl 1):13-21.

Goldman L, Eskenazi B, Bradman A, Jewell NP. 2004. Risk behaviors for pesticide exposure among pregnant women living in farmworker households in Salinas, California. Am J Ind Med 45:491-499.

Gomes J, Lloyd OL, Revitt DM. 1999. The influence of personal protection, environmental hygiene and exposure to pesticides on the health of immigrant farm workers in a desert country. Int Arch Occup Environ Health 72:40-45.

Hernandez-Valero MA, Bondy ML, Spitz MR, Zahm SH. 2001. Evaluation of Mexican American migrant farmworker work practices and organochlorine pesticide metabolites. Am J Ind Med 40:554-560.

Keifer MC. 2000. Effectiveness of interventions in reducing pesticide overexposure and poisonings. Am J Ind Med 18:80-89.

Keifer MC, Wesseling C, McConnell R. 2004. Pesticides and related compounds. In: Rosenstock L, Cullen MR, Brodkin CA, Redlich CA, editors. Textbook of clinical occupational and environmental medicine. 2nd edition. Philadelphia: W.B. Saunders Company. p 1099-1126.

Lantz PM, Dupuis L, Reding D, Krauska M, Lappe K. 1994. Peer discussions of cancer among Hispanic migrant farm workers. Public Health Rep 109:512-520.

Little RJA, Rubin DB. 1987. Statistical analysis with missing data. 2nd edition. New York: Wiley.

Lu C, Fenske RA, Simcox NJ, Kalman D. 2000. Pesticide exposure of children in an agricultural community: Evidence of household proximity to farmland and take home exposure pathways. Environ Res 84:290-302.

McCauley LA, Lasarev MR, Higgins G, Rothlein J, Muniz J, Ebbert C, Phillips J. 2001. Work characteristics and pesticide exposures among migrant agricultural families: A community-based research approach. Environ Health Perspect 109:533-538.

McCauley LA, Michaels S, Rothlein J, Muniz J, Lasarev M, Ebbert C. 2003. Pesticide exposure and self reported home hygiene: Practices in agricultural families. AAOHN J 51:113-119.

Mobed K, Gold EB, Schenker MB. 1992. Occupational health problems among migrant and seasonal farm workers. West J Med 157:367-373.

Moses M. 1989. Pesticide-related health problems and farmworkers. AAOHN J 37:115-130.

National Institutes of Occupational Safety and Health. 1995. Report to Congress on Workers' Home Contamination Study conducted under the Workers' Family Protection Act: U.S. Department of Health and Human Services, CDC/NIOSH.

Prado JB, Vanderslice J. 2004. Learning from Listening: Results of Yakima Farmworker Focus Groups about Pesticides and Health Care: Washington State Department of Health.

Quandt SA, Arcury TA, Austin CK, Cabrera LF. 2001. Preventing occupational exposure to pesticides: Using participatory research with latino farmworkers to develop an intervention. J Immigr Health 3:85-96.

Quandt SA, Hernandez-Valero MA, Grzywacz JG, Hovey JD, Gonzales M, Arcury TA. 2006. Workplace, household, and personal predictors of pesticide exposure for farmworkers. Environ Health Perspect 114:943-952.
Raghunathan TE. 2004. What do we do with missing data? Some options for analysis of incomplete data. Annu Rev Public Health 25:99-117.

Ramirez AG, Suarez L, Laufman L, Barroso C, Chalela P. 2000. Hispanic women's breast and cervical cancer knowledge, attitudes, and screening behaviors. Am J Health Promot 14:292-300.

Rao P, Gentry AL, Quandt SA, Davis SW, Snively BM, Arcury TA 2006. Pesticide safety behaviors in Latino farmworker family households. Am J Ind Med 49:271-280.

Rosenstock IM. 1990. The Health Belief Model: Explaining health behavior through expectancies. In: Glanz K, Lewis FM, Rimer BK, editors. Health behavior and health education: Theory, research, and practice San Francisco. CA: Jossey-Bass. p 39-62.

Royston P. 2004. Multiple imputation of missing values. Stata J 4:227_ 241.

Royston P. 2005. Multiple imputation of missing values: Update. Stata J 5:188-201.

Rubin DB. 1987. Multiple imputation for nonresponse in surveys. New York: Wiley.

Salazar MK. 1996. Hispanic women's beliefs about breast cancer and mammography. Cancer Nurs 19:437-446.

SAS Institute Inc. 2004. SAS/STAT User's Guide, Version 9.1 Cary. NC: SAS Institute Inc.

Simcox NJ, Fenske RA, Wolz SA, Lee IC, Kalman DA. 1995. Pesticides in household dust and soil: Exposure pathways for children of agricultural families. Environ Health Perspect 103:1126-1134.

Spencer JR, Sanborn JR, Hernandez BZ, Krieger RI, Margetich SS, Schneider FA. 1995. Long vs. short monitoring intervals for peach harvesters exposed to foliar azinphos-methyl residues. Toxicol Lett 78 $17-24$

StataCorp. 2003. STATA Statistical Software: Release 8.0 College Station. TX: Stata Corporation.

Thompson B, Coronado G, Solomon C, McLerran DF, Neuhauser ML, Feng Z. 2002. Cancer prevention behaviors and socioeconomic status among Hispanics and non-Hispanic Whites in a rural population in the United States. Cancer Causes Control 13:719-728.

Thompson B, Coronado GD, Grossman JE, Puschel K, Solomon CC, Islas I, Curl CL, Shirai JH, Kissel JC, Fenske RA. 2003. Pesticide takehome pathway among children of agricultural workers: Study design, methods, and baseline findings. J Occup Environ Med 45:42-53.

U.S. Bureau of the Census. 2004. U.S. Census Bureau, detailed tables: Yakima County, Washington. American FactFinder Washington. D.C: U.S. Bureau of the Census.

United States Environmental Protection Agency. 1992. Worker Protection Standard. 40 CFR Part 170.

United States Environmental Protection Agency. 1995. Steps to protect yourself from pesticides (Spanish). Prevention, pesticides, and toxic substances (7506C). EPA 735-F-95-002.

Van Buuren S. 1999. Multiple imputation of missing blood pressure covariates in survival analysis. Stat Med 18:681-694.

Vaughan E. 1993. Chronic exposure to an environmental hazard: Risk perceptions and self-protective behavior. Health Psychol 12:74-85.

Yuan YC. 2000. Multiple Imputation for Missing Data: Concepts and New Development. Proceedings of the 25th Annual SAS Users Group International Conference Indianapolis: Abstract p 225-267. 